\title{
Synthesis and characterisation of functionalized borosilicate nanoparticles for boron neutron capture therapy applications
}

\author{
S. Grandi $\cdot$ A. Spinella $\cdot$ C. Tomasi $\cdot$ \\ G. Bruni $\cdot$ M. Fagnoni $\cdot$ D. Merli $\cdot$ P. Mustarelli $\cdot$ \\ G. F. Guidetti · C. Achilli · C. Balduini
}

Received: 19 June 2012/ Accepted: 16 August 2012/Published online: 14 September 2012

(C) Springer Science+Business Media, LLC 2012

\begin{abstract}
Boron Neutron Capture Therapy (BNCT) is a promising therapy for the cure of diffuse tumors. The successful clinical application of BNCT requires finding new boron-based compounds suitable for an efficient ${ }^{10} \mathrm{~B}$ delivery to the cancerous tissues. The purpose of this work is to synthesize borosilicate nanoparticles by a sol-gel recipe, and to functionalize them with folic acid in order to promote their capture by the tumor cells. Whereas sol-gel is a promising technique for the synthesis of nanoparticles, in case of borosilicate systems this approach is affected by significant boron loss during preparation. Here we show that functionalization of borosilicate nanoparticles with folic acid can reduce the boron loss. Moreover, preliminary biocompatibility tests indicate that functionalization strongly changes the reactivity of NPs towards blood cells, so favouring the potential use of these materials for clinical applications.
\end{abstract}

S. Grandi ( $)$ · G. Bruni · M. Fagnoni · D. Merli ·

P. Mustarelli

Department of Chemistry, University of Pavia,

V.le Taramelli 12, 27100 Pavia, Italy

e-mail: rondine68cub@yahoo.it

A. Spinella

CGA, University of Palermo, 14, Via F. Marini,

90128, Palermo, Italy

C. Tomasi

I.E.N.I. C.N.R. Department of Pavia,

Viale Taramelli 16, 27100 Pavia, Italy

G. F. Guidetti - C. Achilli - C. Balduini

Laboratory of Biochemistry, Department of Biology

and Biotechnology, University of Pavia,

Via Bassi 21, 27100 Pavia, Italy
Keywords Nanoparticles - Borosilicate Folic acid · BNCT

\section{Introduction}

Boron neutron capture therapy (BNCT) can potentially destroy cancer cells in a selective way so minimizing negative effects on healthy tissues. This treatment is based on the selective accumulation into the malignant cells of ${ }^{10} \mathrm{~B}$-containing compounds administrated by intravenous infusion. Subsequent thermal neutron irradiation promotes ${ }^{10} \mathrm{~B}$ decay to one ${ }^{4} \mathrm{He}\left(\alpha\right.$ particle) and one ${ }^{7} \mathrm{Li}$ atom with a cytotoxic effect that can destroy the tumor cell [1]. To date, medical trials of BNCT had been carried out principally with boronophenylalanine (BPA) that showed a good selectivity to malignant cells. On the other hand, BPA contains only the $5.1 \%$ wt. of boron.

Many classes of nanomaterials are under investigation as possible boron-carriers in alternative to BPA [2, 3]. Functionalization with folic acid improves their uptake in tumor cell lines $[4,5,6]$, probably due to the overexpression of folic acid receptors in many types of cancer cells. An example of boron-enriched nanomaterial are Boron Nitride Nanotubes (BNNTs) functionalized with folic acid, recently studied by Ciofani et al. [6], who reported a good uptake on malignant glioblastoma cells. Unfortunately, an important disadvantage of BNNTs is their availability, as to date the production is expensive and limited to the laboratory scale.

As an alternative, it is possible to employ borosilicate porous glasses obtained by sol-gel method which are biocompatible, bioactive and biological resorbable [7]. However, it is difficult to prepare these particles with a 
high boron concentration because of the nature of $\mathrm{B}-\mathrm{O}-\mathrm{Si}$ bond that is highly hydrolysable in presence of water (humidity). Many authors reported significant boron lack in their sol-gel samples. Nogami and Moriya [8] prepared different compositions of $\mathrm{SiO}_{2}-\mathrm{B}_{2} \mathrm{O}_{3}$ and their study showed that for the sample containing more than $20 \mathrm{~mol} \%$ $\mathrm{B}_{2} \mathrm{O}_{3}$ a quarter of $\mathrm{B}_{2} \mathrm{O}_{3}$ was lost during the gel synthesis. The problem of the of $\mathrm{Si}-\mathrm{O}-\mathrm{B}$ bond formation was analyzed by Irwin et al. [9, 10] by means of ${ }^{29} \mathrm{Si}$ and ${ }^{11} \mathrm{~B}$ MAS NMR spectroscopy. They showed that the majority of boron atoms in xerogels was in form of boric acid hydrogen-bonded to the silica network, whereas there was only a small amount of B-O-Si bonds. They concluded that the boron leaching was due both to the presence of water and to the high volatility of the trimethoxyborate reagent. Only a thermal treatment performed at about $500{ }^{\circ} \mathrm{C}$ was able to transform the boric acid hydrogen-bonded to the silica matrix into a true borosiloxane network. Later in $2002, \mathrm{Li}$ et al. [11] reported both synthesis and characterization of the ternary system $\mathrm{SiO}_{2}-\mathrm{B}_{2} \mathrm{O}_{3}-\mathrm{P}_{2} \mathrm{O}_{5}$ with different molar ratio. However, in such a paper the loss of boron was hypothesized but not quantified. Soraru et al. [12, 13] found that $\mathrm{SiO}_{2}-\mathrm{B}_{2} \mathrm{O}_{3}$ gels made by employing organo-modified silicon alkoxides did retain boron in the xerogels by means of the creation of a high number of borosiloxane bonds. Nonetheless, when the boron content was verified by elemental analysis [13], the loss of boron was still detected (about 20-50\%). A very recent work [14] proposed a particular sol-gel synthesis of borosilicate nanoparticles (100-500 nm) by exothermic phase separation, but the real boron content was not verified. Our very recent study [15] on borosilicate xerogels revealed the same problem, which was partially overcame by employing 3-aminopropyltriethoxysilane (APTES) as a co-precursor. These findings are promising for possible application in BNCT therapy: in fact, pre-functionalization of nanoparticles with $-\mathrm{NH}_{2}$ groups allows the further functionalization with folic acid and could improve the uptake in tumor cells. In this way the presence of $-\mathrm{NH}_{2}$ groups would play a dual role: as a boron trapper and a primer.

Aim of this work is the preparation of NPs from $2 \mathrm{SiO}_{2}$ $-\mathrm{B}_{2} \mathrm{O}_{3}$ xerogels with a top-down method, and their functionalization with folic acid. Many authors have also reported that different classes of nanomaterials are not completely inert toward biological systems and can exert several toxic effects [16, 17]. Furthermore, nanoparticles can induce negative responses of blood components, including neutrophil activation [18] and platelet aggregation $[19,20]$. Therefore, biocompatibility tests on platelets and neutrophils were performed in order to evaluate whether borosilicate NPs, and the corresponding folate-functionalized counterparts, can be suitable for intravenous injection for BNCT.

\section{Experimental}

\subsection{Preparation of $2 \mathrm{SiO}_{2}-\mathrm{B}_{2} \mathrm{O}_{3}$ xerogel (sample $\mathrm{SiB}$ )}

$10.39 \mathrm{~g}$ of trimethylborate (TMB) were dissolved in $30 \mathrm{ml}$ of methanol and $3.6 \mathrm{ml}$ of $\mathrm{H}_{2} \mathrm{O}$, and stirred for $1 \mathrm{~h}$ in order to complete the hydrolysis stage, then $15.22 \mathrm{~g}$ of tetramethoxysilane (TMOS) were slowly added and the "sol" was stirred again for $4 \mathrm{~h}$. Finally, the sol was poured in closed containers and kept in an oven at $50{ }^{\circ} \mathrm{C}$. Gelation occurred in 6 days. Then gel was dried as xerogel for about 2 weeks at $50{ }^{\circ} \mathrm{C}$.

\subsection{Preparation of pre-functionalized $2 \mathrm{SiO}_{2}-\mathrm{B}_{2} \mathrm{O}_{3}$ xerogel (sample SiBNH2)}

$10.39 \mathrm{~g}$ of TMB were dissolved in $15 \mathrm{ml}$ of methanol and $3.6 \mathrm{ml}$ of $\mathrm{H}_{2} \mathrm{O}$ and stirred for $1 \mathrm{~h}$ in order to complete the hydrolysis stage. Then $11.41 \mathrm{~g}$ of TMOS were slowly added and the sol was stirred for $1 \mathrm{~h}$. Separately, $5.53 \mathrm{~g}$ of aminopropyltriethoxysilane (APTES) which is $25 \% \mathrm{~mol}$ of the total $\mathrm{Si}$, were added to $10 \mathrm{ml}$ of ethanol and $1.35 \mathrm{ml}$ of $\mathrm{H}_{2} \mathrm{O}$ and stirred for $1 \mathrm{~h}$. Finally, the sol of APTES was slowly added to the first sol which turned opaque and gelation occurred in $10 \mathrm{~min}$. The gels were dried for about 3 weeks in an oven at $50{ }^{\circ} \mathrm{C}$.

\subsection{Top-down method for nanoparticles (NPs) production}

Xerogel samples were ground manually in an agate mortar and afterwards milled by a high performance planetary milling machine (FRITSCH Pulverisette 7) with speeds ranging between 300 and $850 \mathrm{rpm}$, by repeating 24 times the cycle run $=30 \mathrm{~min}$; pause $=20 \mathrm{~min}$.

\subsection{Functionalization of NPs with folic acid (sample SiBNH2_F)}

$2.65 \mathrm{~g}$ of folic acid were dissolved in $15 \mathrm{ml}$ of dry dimethylsulfoxide (DMSO) in a $100 \mathrm{ml}$ round bottom flask under $\mathrm{N}_{2}$ atmosphere, then $2.3 \mathrm{~g}$ of 1-ethyl-3-(3-dimethylaminopropyl)carbodiimide hydrochloride (EDC), $0.69 \mathrm{~g}$ of N-hydroxy succinimide (NHS) and $0.5 \mathrm{ml}$ of pyridine were added. The reaction mixture was stirred at room temperature for $1 \mathrm{~h}$. Then $3 \mathrm{~g}$ of glass nanoparticles were added to the flask and the reaction mixture was kept overnight under magnetic stirring. The mixture was then filtered on suction and the resulting yellowish residue was washed twice times with DMSO under sonication, then twice in water and acetonitrile under sonication and then centrifuged. The final NPs were obtained upon washing with ethyl alcohol and acetone followed by centrifugation 
and dryness. This cumbersome washing procedure was necessary to remove the folic acid adsorbed on the nanoparticles surface, accounting as much as 25 wt $\%$ without washing (TGA analysis, data not shown).

\subsection{ICP-OES analysis}

About $60 \mathrm{mg}$ (exactly weighed) of each sample, were digested overnight at room temperature with $0.2 \mathrm{ml} 40 \%$ $\mathrm{HF}$ and $0.2 \mathrm{ml} 65 \% \mathrm{HNO}_{3}$ in a closed PET vessel and then diluted with milliQ water to $50 \mathrm{ml}$. The boron concentration in the digested samples, diluted 1:10, was measured by inductively coupled plasma spectroscopy (ICP-OES). An ICP-OES Perkin Elmer Optima 3300 DV was used for all the measurements, following the operating conditions suggested by the manufacturers (in radial view). A linear relationship between the signal intensity and boron concentration $\left(0.030-20 \mathrm{mg} \mathrm{l}^{-1}\right.$ ) was obtained by using standard solutions daily prepared from a $1.001 \mathrm{mg} \mathrm{ml}^{-1}$ stock solution. $\mathrm{LOD}=10 \mu \mathrm{gL}^{-1}, \mathrm{LOQ}=30 \mu \mathrm{gL}^{-1}$. All data were corrected in order to take into account the humidity of the sample. The water content was determined by TGA analysis.

\subsection{Thermal analysis}

Thermogravimetric scans were performed by a TGA 2950 (TA Instruments) under $\mathrm{O}_{2}$ purge, at a heating rate of $5{ }^{\circ} \mathrm{C} / \mathrm{min}$, from room temperature up to $900{ }^{\circ} \mathrm{C}$. Differential scanning calorimetry measurements were carried out by means of a $2910 \mathrm{DSC}$ (TA Instruments) under $\mathrm{O}_{2}$ purge at $5{ }^{\circ} \mathrm{C} / \mathrm{min}$ from room temperature up to $300{ }^{\circ} \mathrm{C}$. The upper limited temperature was chosen to prevent cell contamination during sample decomposition.

\subsection{FT-IR spectroscopy}

Reflectivity spectra were obtained between 600 and $4000 \mathrm{~cm}^{-1}$ by using a FT-IR 410 JASCO spectrometer. The samples were finely mixed with $\mathrm{KBr}$ (about 5 wt $\%$ of sample), and the spectra were obtained by subtraction with a blank one (pure $\mathrm{KBr}$ ). The signals were averaged over 512 scans, with a resolution of $2 \mathrm{~cm}^{-1}$ and a scan velocity of $2 \mathrm{~mm} / \mathrm{s}$. Spectra were reported as transmittance mode.

\subsection{Solid state NMR}

${ }^{13} \mathrm{C}\left\{{ }^{1} \mathrm{H}\right\}$ CPMAS NMR spectra were acquired by means of a Bruker Avance Spectrometer II 400 (9.4 T), with a MAS frequency of $13 \mathrm{kHz}$, a ${ }^{1} \mathrm{H} 90^{\circ}$ pulse at of $4.2 \mu \mathrm{s}$, contact time of $1.5 \mathrm{~ms}$, delay time of $4 \mathrm{~s}$ and 4000 acquisitions. Hartman-Hahn condition was optimized on a standard of adamantane.

\subsection{SEM}

Microphotographs were collected with a Zeiss EVO-MA10 (Carl Zeiss, Oberkochen, Germany) on gold sputtered samples.

\subsection{Preparation of NP suspensions}

NPs were suspended in phosphate buffer saline (PBS, $5 \mathrm{mM}$ sodium phosphate at $\mathrm{pH} 7.4,154.5 \mathrm{mM} \mathrm{NaCl}$, $4.5 \mathrm{mM} \mathrm{KCl}$ ) at the concentration of $3 \mathrm{mg} / \mathrm{ml}$. An ultrasound treatment of $5 \mathrm{~min}$ were performed three times to deagglomerate homogeneously the NPs, using a probe sonication device (Soniprep 150, Sanyo).

\subsection{Analysis of platelet aggregation}

Platelet aggregation analysis was performed as previously described [20]. Briefly, 0.3-ml samples of washed human platelets at the final concentration of $3 \times 10^{8}$ cells $/ \mathrm{ml}$ were stimulated with the reported doses of NPs in a Born lumiaggregometer at $37{ }^{\circ} \mathrm{C}$ in the presence of $1 \mathrm{mM}$ $\mathrm{CaCl}_{2}$. Platelet aggregation, measured as the variation of light transmission, was monitored for $5 \mathrm{~min}$.

\subsection{Analysis of neutrophil activation}

Neutrophils were obtained from human venous blood by Dextran-70 sedimentation followed by Ficoll-Hypaque gradient centrifugation, essentially as described in [21] and washed in PBS supplemented with $2 \mathrm{mM}$ EDTA, $0.5 \%$ $(\mathrm{w} / \mathrm{v})$ bovine serum albumin and $0.1 \%(\mathrm{w} / \mathrm{v})$ glucose. The residual erythrocytes in the neutrophil-rich fraction were eliminated by differential hypotonic lysis. The samples for the assay (150 $\mu \mathrm{l}$, final volume) were prepared as shown below (final concentrations): neutrophils $\left(2 \times 10^{4}\right.$ cells/ $\mu \mathrm{l})$, luminol $(10 \mu \mathrm{M})$, sodium phosphate $\mathrm{pH} 7.4(5 \mathrm{mM})$, $\mathrm{NaCl}(154.5 \mathrm{mM}), \mathrm{KCl}(4.5 \mathrm{mM}), \mathrm{MgCl}_{2}(1 \mathrm{mM}), \mathrm{CaCl}_{2}$ $(0.6 \mathrm{mM})$. After the addiction of NPs $(1 \mathrm{mg} / \mathrm{ml})$ or phorbol myristate acetate (PMA, $0.8 \mu \mathrm{M}$ ), neutrophil activation was monitored by luminol-enhanced chemiluminescence method in a 96-wells microtiter plate reader (Genios Plus, Tecan) for $60 \mathrm{~min}$, at $37{ }^{\circ} \mathrm{C}$ and under stirrer. The samples were made in quadruplicate (Fig. 1).

\section{Results and discussion}

Sol-gel synthesis, as expected, leads to a sample with a low boron content: the amount of boron, as analyzed by ICPOES, was $1.2 \mathrm{wt} \%$. Considering that the theoretical amount should be 11.4 wt $\%$ ( $\mathrm{B}$ as $\mathrm{B}_{2} \mathrm{O}_{3}$ ), the boron loss is about $89 \%$. Sol-gel synthesis of a prefunctionalized system 
Fig. 1 Reaction of functionalization of borosilicate nanoparticles with folic acid<smiles></smiles>

Folic acid

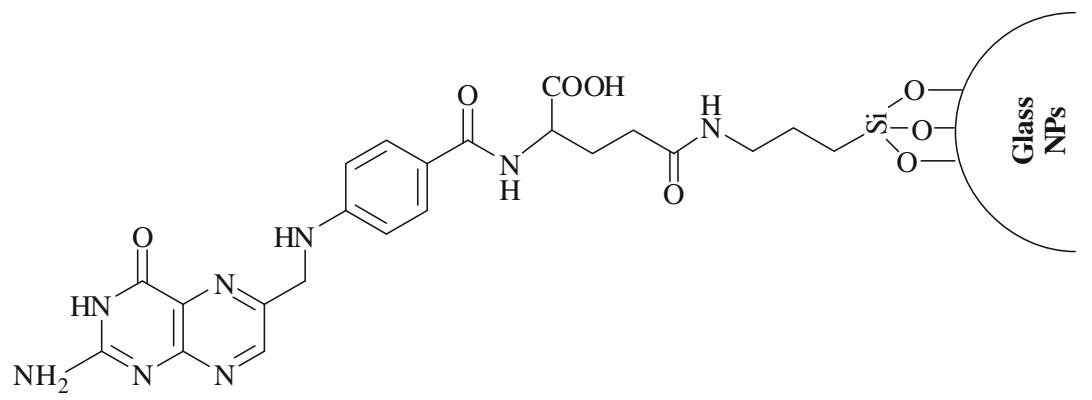

$2 \mathrm{SiO}_{2}-\mathrm{B}_{2} \mathrm{O}_{3}$, with the presence of $-\mathrm{CH}_{2} \mathrm{CH}_{2} \mathrm{CH}_{2} \mathrm{NH}_{2}$ groups gave an experimental boron content of about 4.4 wt \%. In this case, the theoretical amount of B is about 8 wt $\%$, then boron loss is strongly reduced (about $45 \%$ compared to $89 \%$ ). After functionalization with folic acid, the final amount of B is $2.7 \mathrm{wt} \%$, which means that a significant further boron loss does not occur in the functionalization procedure (see TGA results). Figure 2 shows the TGA data of the following samples: (1) SiB; (2) SiBNH2; (3) SiBNH2_F. Non-functionalized SiB sample exhibits a total weight loss of about $13 \%$ at $800{ }^{\circ} \mathrm{C}$, the first single-step weight decrease below $200{ }^{\circ} \mathrm{C}$ is due to the moisture removal and eventual trimethoxyborate evaporation, while the second continuous weight decrease could be due to condensation of $-\mathrm{OH}$ groups, a typical feature of xerogel samples. The pre-functionalized SiBNH2 sample shows a weight loss of $26.5 \%$ at $800{ }^{\circ} \mathrm{C}$. Similar considerations as for $\mathrm{SiB}$ can be made at low temperatures, whereas the more evident step decrease between 300 and $600{ }^{\circ} \mathrm{C}$ could be ascribed to decomposition of the $-\mathrm{CH}_{2} \mathrm{CH}_{2} \mathrm{CH}_{2} \mathrm{NH}_{2}$ groups. By considering the difference in moisture content between $\mathrm{SiBNH} 2$ and $2 \mathrm{SiB}$, one can estimate an experimental loss of the organic part of about 10-11 wt \%, compared to a theoretical value ranging around $13 \mathrm{wt} \%$. The SiBNH2_F sample exhibits a total weight loss of about $42 \%$, which this value is compatible with the $50 \mathrm{wt} \%$ expected if admitting that all the $-\mathrm{NH}_{2}$ groups do react with folic acid. Figure 3 reports the DSC data of the same three samples. The non-functionalized sample $2 \mathrm{SiB}$ exhibits a broad endothermic peak up to $\approx 200{ }^{\circ} \mathrm{C}$ related to moisture removal, and no apparent events can be detected at least up to $300{ }^{\circ} \mathrm{C}$. The pre-functionalized $\mathrm{SiBNH} 2$ sample shows the endothermic effect due to moisture release around $100{ }^{\circ} \mathrm{C}$, followed by an exothermic feature at $\approx 250{ }^{\circ} \mathrm{C}$ likely due to incipient decomposition of the $\mathrm{CH}_{2} \mathrm{CH}_{2} \mathrm{CH}_{2} \mathrm{NH}_{2}$ groups. The functionalized SiBNH2_F sample displays a tiny endotherm below $150{ }^{\circ} \mathrm{C}$ corresponding to the little amount of moisture contained in such a specimen, which is more hydrophobic thanks to the presence of folic acid. Even in this case, the exothermic profile above $200{ }^{\circ} \mathrm{C}$ can be related to incipient decomposition of the organic part.

The functionalization reaction was firstly monitored by IR spectroscopy. Figure 4 shows the IR spectra of the prefunctionalized sample SiBNH2, the functionalized one and the folic acid. For SiBNH2 sample the broad band between 1300 and $1500 \mathrm{~cm}^{-1}$ is due to the stretching of $\mathrm{B}-\mathrm{O}$ bonds where $\mathrm{B}$ is in planar trigonal coordination, whereas the second broad band between 1000 and $1200 \mathrm{~cm}^{-1}$ is due to both the $\mathrm{Si}-\mathrm{O}-\mathrm{Si}$ and $\mathrm{B}-\mathrm{O}-\mathrm{B}$ groups. Some very weak bands between 2300 and $2500 \mathrm{~cm}^{-1}$ can be attributed to the borate group. In fact, our previous study [15] showed that when $[\mathrm{B}]$ is less than $3 \mathrm{wt} \%$ it is very difficult to detect the six typical borate bands in this region. The band at $3200 \mathrm{~cm}^{-1}$, corresponding to the $-\mathrm{OH}$ stretching of $\mathrm{B}-\mathrm{OH}$, is slightly evident inside the broad band between 3200 and $3700 \mathrm{~cm}^{-1}$ due to the $\mathrm{OH}$ stretching of both 


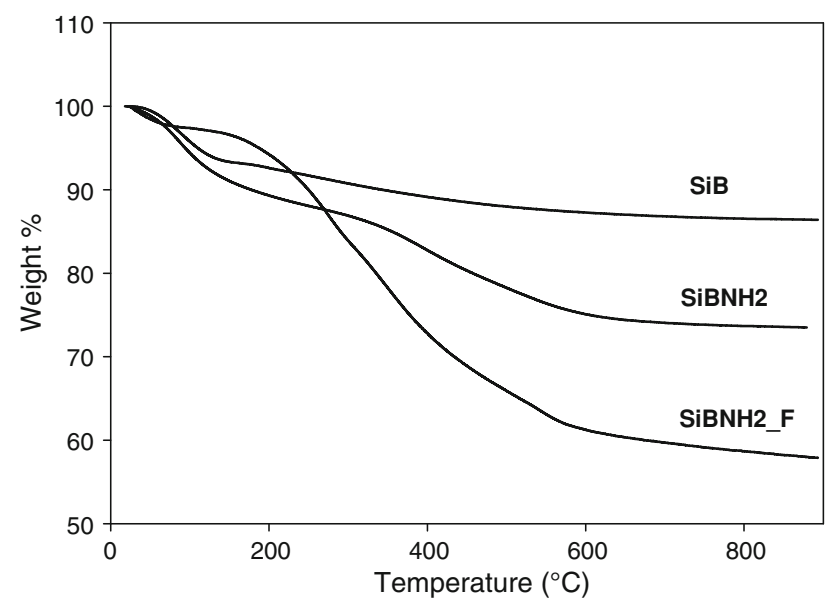

Fig. 2 TGA traces of samples $\mathrm{SiB}, \mathrm{SiBNH} 2$ and $\mathrm{SiBNH} 2 \_\mathrm{F}$

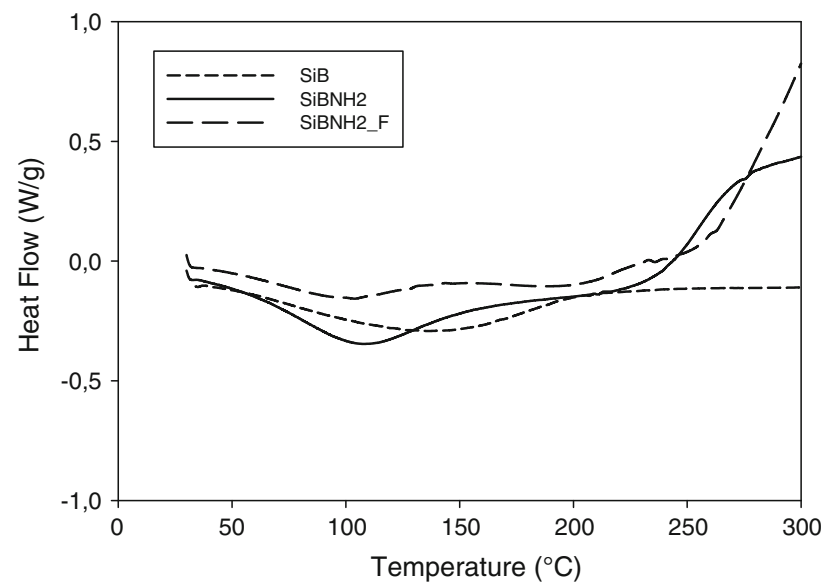

Fig. 3 DSC traces of samples $\mathrm{SiB}, \mathrm{SiBNH} 2$ and $\mathrm{SiBNH} 2$ _F

silanol groups and water. The band at around $1635 \mathrm{~cm}^{-1}$ confirms the presence of free water molecules. Unfortunately, some typical signals of the group $-\mathrm{NH}_{2}$ could not be detected because they were completely masked by those of free-water and $-\mathrm{OH}$ groups. The presence of signals due to the $-\mathrm{CH}_{2} \mathrm{CH}_{2} \mathrm{CH}_{2} \mathrm{NH}_{2}$ groups is mixed with the above cited broad band between 1000 and $1200 \mathrm{~cm}^{-1}$.

The IR spectrum of the folic acid is very complex, the signals are not completely assigned, and there is not full agreement in the literature about the interpretation of some bands. For example $\mathrm{He}$ et al. [22] ascribed the bands between 3400 and $3600 \mathrm{~cm}^{-1}$ both to $-\mathrm{OH}$ stretching of the glutamic acid portion and to $-\mathrm{NH}$ stretching of the pterinic portion. Then, bands between 1510 e $1485 \mathrm{~cm}^{-1}$ are due to the $\mathrm{C}-\mathrm{C}$ vibrations of phenolic and pterinic ring. The same authors ascribed the broad and complex band at $1696 \mathrm{~cm}^{-1}$ to the stretching of different $-\mathrm{C}=\mathrm{O}$ groups, and the band at $1607 \mathrm{~cm}^{-1}$ to the bending of $-\mathrm{NH}$ groups. In contrast, Yang et al. [23] assigned both the band at $1607 \mathrm{~cm}^{-1}$ and the band at $1449 \mathrm{~cm}^{-1}$ to the stretching of

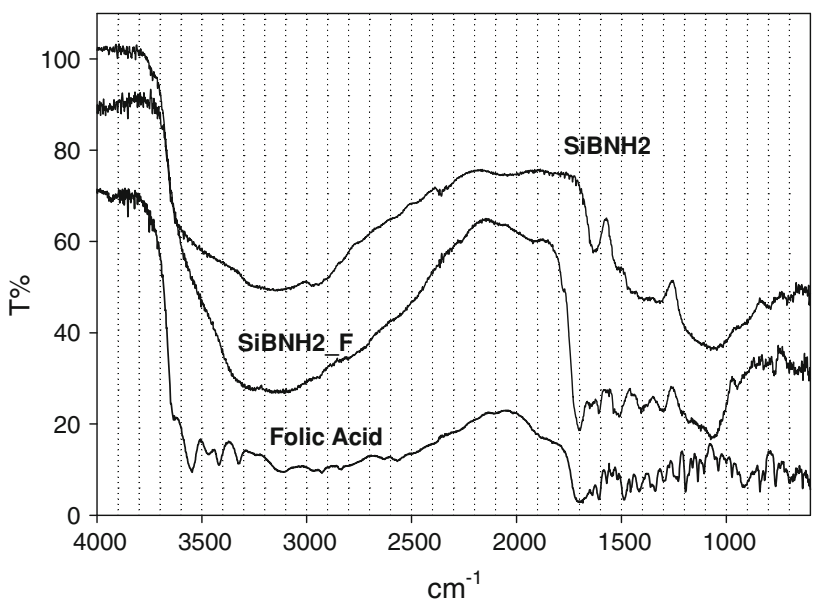

Fig. 4 FT-IR spectra of folic acid and samples $\mathrm{SiBNH} 2$ and SiBNH2_F

aromatic $\mathrm{C}=\mathrm{C}$ bonds. Vora et al. [24] assigned the bands between 2860 and $2960 \mathrm{~cm}^{-1}$ to the symmetric and antisymmetric stretching of $\mathrm{C}-\mathrm{H}$ bonds. All the cited authors agreed in assigning the multiple band at $1696 \mathrm{~cm}^{-1}$ to the stretching of different $-\mathrm{C}=\mathrm{O}$ groups. The IR spectrum of sample SiBNH2_F, in particular the region between 1200 and $1700 \mathrm{~cm}^{-1}$ indicates the presence of folic acid but it is very difficult to detect the formation of the new -NHCObond. In fact, a secondary amide group is still present in the folic acid molecule and it is impossible to distinguish it from the new one (also secondary). A similar consideration can be done with respect to the broad signal of the $-\mathrm{COOH}$ group which becomes a -NHCO group, because it falls in the same frequency region of the other $-\mathrm{COOH}$ group, which does not react because sterically hindered and engaged by means of a H-bond (see below).

From these spectra it is possible to state that folic acid is present on the surface of borosilicate NPs, but it is not possible to prove the occurred reaction. Additional information can be obtained by solid-state NMR. Figure 5 reports the CPMAS NMR spectrum of folic acid. According to the SDBS- ${ }^{13} \mathrm{C}$ NMR data base the carbon signals can be easily assigned (see inset of Fig. 5). In particular signals no 1 and no 2 refer to the carboxylic groups. Figure 6 reports the NMR spectrum of the sample SiBNH2. As expected only three signals are evidenced, which are due to the three carbons of the $-\mathrm{CH}_{2} \mathrm{CH}_{2} \mathrm{CH}_{2} \mathrm{NH}_{2}$ group as showed in the inset scheme. Figure 7 shows the NMR spectrum of the NPs functionalized with folic acid. As expected, the signals related to the organic shell of the inorganic borosilicate particle are broader compared to those presented in Fig. 5. The peaks belonging to $\mathrm{CH}_{2} \mathrm{CH}_{2} \mathrm{CH}_{2} \mathrm{NH}_{2}$ are clearly visible (A, $\mathrm{B}, \mathrm{C}$ ), whereas the peak marked with $\mathrm{X}$ is probably due to residual DMSO adsorbed on the particles due to its high boiling point $\left(189^{\circ} \mathrm{C}\right)$. The signals related to folic acid are 
Fig. 5 Solid state ${ }^{13} \mathrm{C}\left\{{ }^{1} \mathrm{H}\right\}$ CPMAS NMR of folic acid

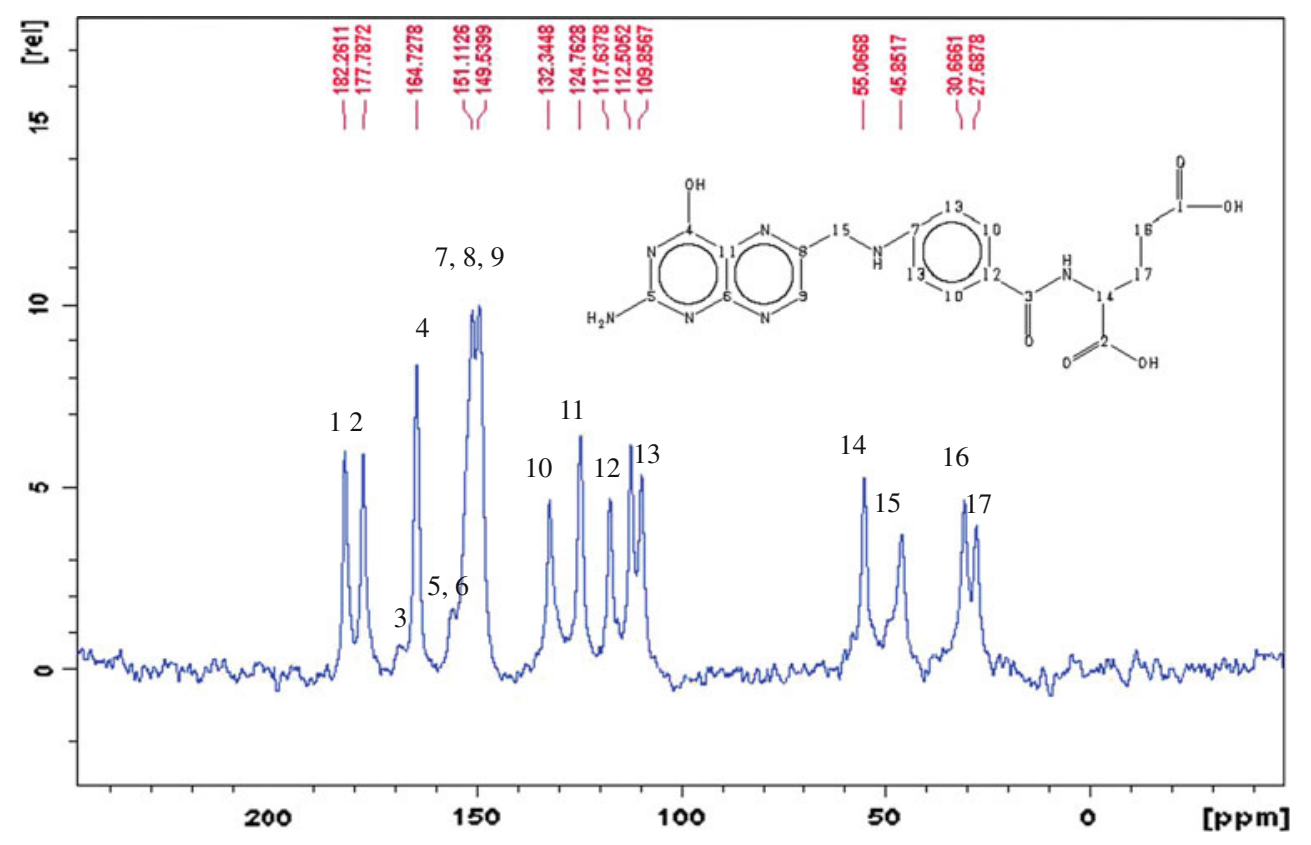

Fig. 6 Solid state ${ }^{13} \mathrm{C}\left\{{ }^{1} \mathrm{H}\right\}$ CPMAS NMR of sample SiBNH2

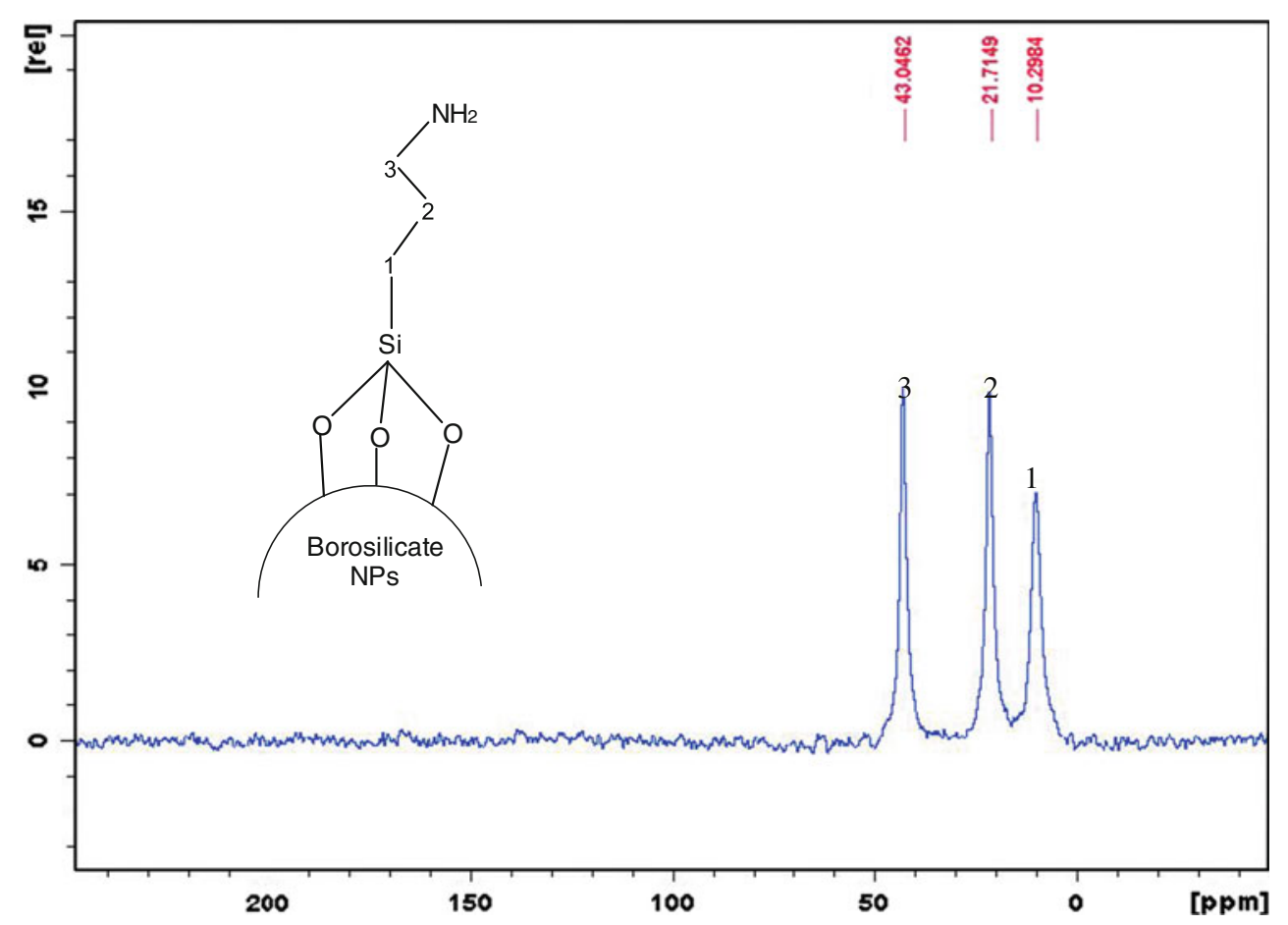

still observable although less definite. The most important difference, indeed, is that signal at about $182 \mathrm{ppm}$ (no 1) related to the reacted carboxylic group disappears, while that signal no 2 related to the second carboxylic group is still present. This occurrence proved that reaction showed in Fig. 1 (the formation of an amide bond) really took place.

For what concerns the particle size, Fig. 8a, b shows the SEM microphotographs of milled pre-functionalized NPs (SiBNH2 sample) and functionalized NPs (SiBNH2_F sample), respectively. Both the samples consist of aggregates of rounded particles. The average diameter of $\mathrm{SiB}$ $\mathrm{NH} 2$ particles ranges between 100 and $200 \mathrm{~nm}$, while the average diameter of $\mathrm{SiBNH} 2 \_F$ particles appears slightly greater, probably because of the functionalization with folic acid on the surface.

As mentioned above, BNCT requires the infusion in the bloodstream of the boron-carrying drug, hence, in order to be suitable for this therapy, the borosilicate NPs must offer 
Fig. 7 Solid state ${ }^{13} \mathrm{C}\left\{{ }^{1} \mathrm{H}\right\}$ CPMAS NMR of sample SiBNH2_F

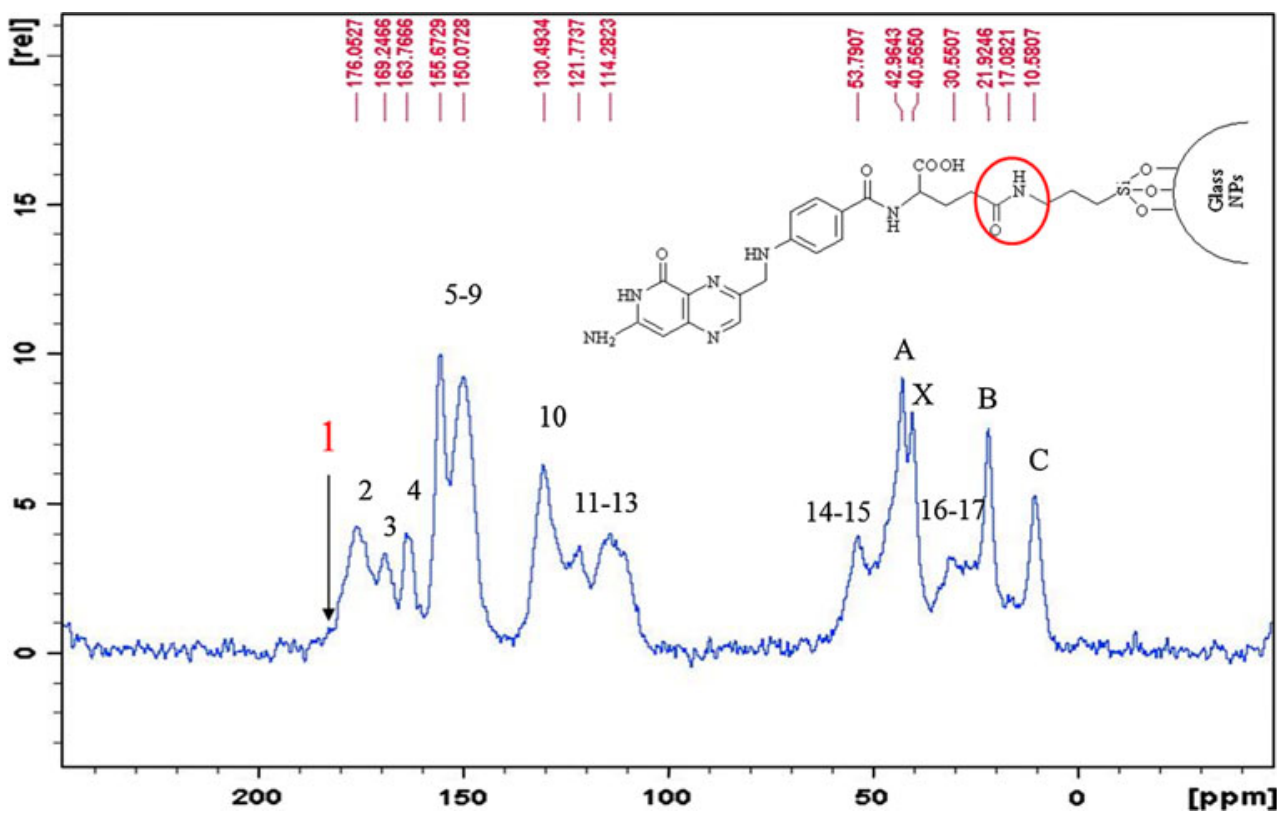

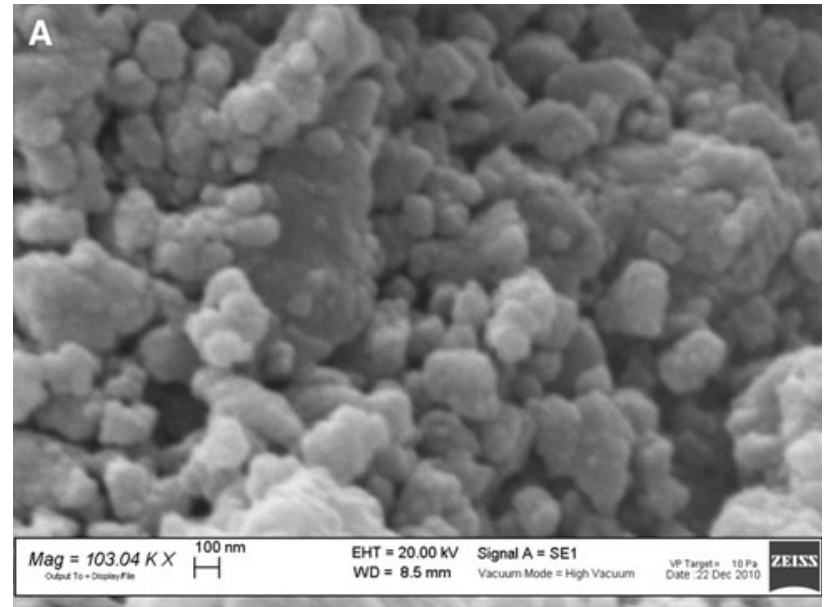

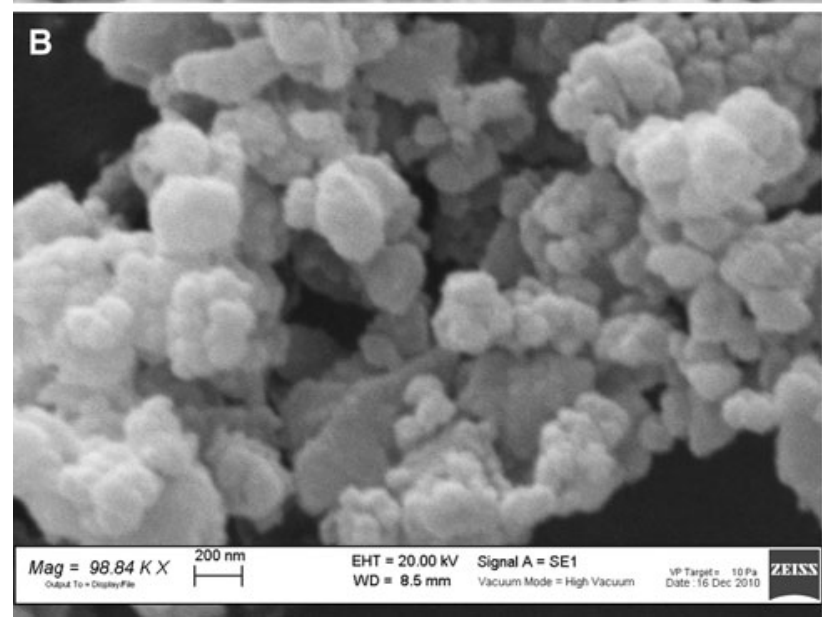

Fig. 8 SEM micrographs of samples SiBNH2 (a) and SiBNH2_F (b) a high level of haemocompatibility. Unfortunately, many types of nanomaterials are effective to stimulate different blood cell types. We focussed our attention on the effects of NPs on platelets and neutrophils. Platelets are key actors in physiological haemostasis, but uncontrolled or unnecessary platelet activation stimulates platelet aggregation and subsequent thrombus formation, which leads to the infarction of the tissues downstream of the occluded vessel [25]. Therefore, ideally, NPs used in BNCT should be completely ineffective in stimulating platelets. In Fig. 9a it is reported that $\mathrm{SiBNH} 2$ at the dose of $100 \mu \mathrm{g} / \mathrm{ml}$ is able to induce a strong platelet aggregation, that is even more evident when the NPs are used at the dose of $500 \mu \mathrm{g} / \mathrm{ml}$. Interestingly, the functionalization with folic acid completely abolished the pro-aggregating activity of NPs, as SiBNH2_F is unable to induce platelet aggregation at both tested doses.

Neutrophils are involved in the innate immunity system and in the inflammatory processes, engulfing the microorganisms and killing it by the release of proteolytic enzymes and several strong oxidative species. Uncontrolled neutrophil activation can induce several inflammatory-dependent diseases [26]. For this reason, the NPs proposed as boron-carrier for BNCT should be totally inert to neutrophils. In Fig. 9b we showed the luminol-enhanced chemiluminescence produced by reaction with the oxidative species released from neutrophils activated by incubation with NPs. The treatment with $\mathrm{SiBNH} 2$, at the dose of $1 \mathrm{mg} / \mathrm{ml}$, induces a strong neutrophil activation, comparable to that observed during PMA stimulation, a typical 

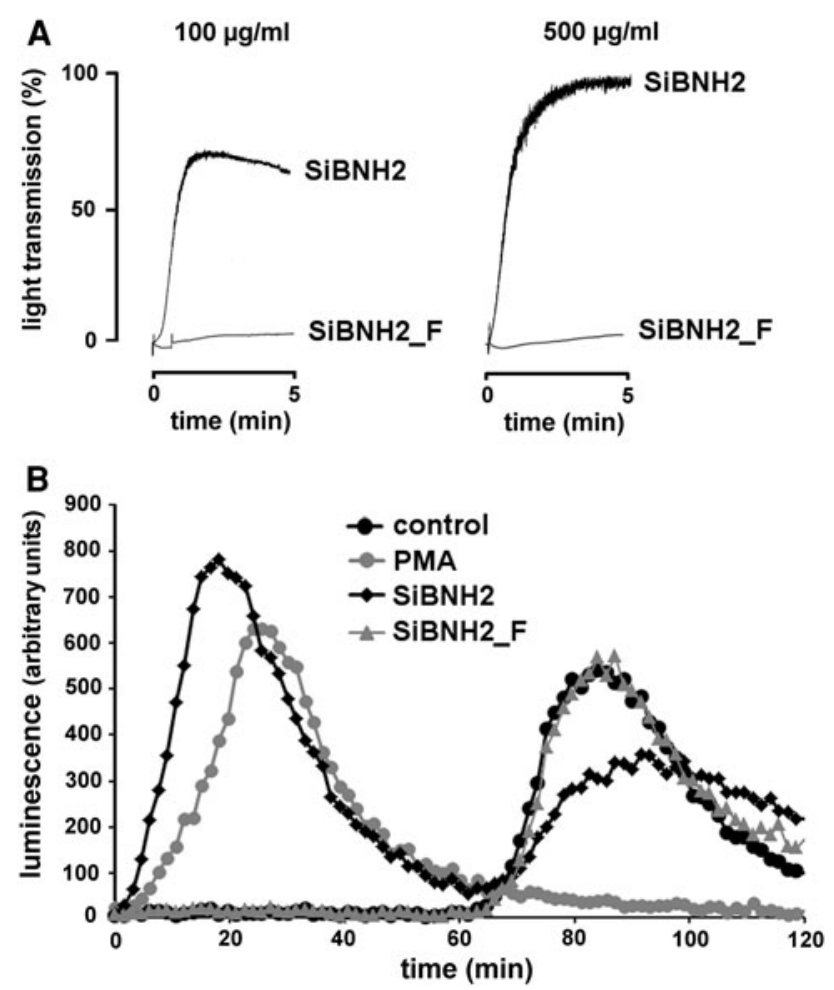

Fig. 9 a Aggregation of human platelets stimulated for 5 min with SiBNH2 and SiBNH2_F (100 and $500 \mu \mathrm{g} / \mathrm{ml}$ ) in a Born aggregometer at $37{ }^{\circ} \mathrm{C}$ under constant stirring. Aggregation was measured continuously as increase of light transmission. b Luminol-induced chemiluminescence of human neutrophil non-stimulated (control), or treated with: SiBNH2, SiBNH2_F and PMA. Following one hour of incubation, the samples "control", "SiBNH2" and "SiBNH2_F" were added with PMA, and the chemiluminescence was monitored for another hour

neutrophil activator. Conversely, the treatment with the same dose SiBNH2_F does not induce neutrophil activation. To verify if the apparent lack of pro-inflammatory property of SiBNH2_F was conversely due to a cell death during incubation, PMA was added to the samples (excepted the one already treated with PMA) and chemiluminescence was monitored again, showing that neutrophils pre-treated with SiBNH2_F have the same intensity of activation of untreated neutrophils (control). Both cytotoxic and pro-inflammatory properties of functionalized NPs were thus excluded. Borosilicate NPs are not cytotoxic for neutrophils at the concentration used in these experiments, but $\mathrm{SiBNH} 2$ have a high pro-inflammatory property that is completely abolished by functionalization with folic acid.

\section{Conclusions}

Borosilicate NPs were obtained by means of a top-down approach from a suitable xerogels system. NPs were successfully functionalized with folic acid. The procedure of pre-functionalization of NPs with amino groups solved two problems at the same time: the boron leaching and subsequent functionalization with folic acid. The functionalization of NPs does not significantly increase the boron loss, and the final amount of $\mathrm{B}$ in the particles is 2.7 wt $\%$. By considering that standard BPA has a boron content of about $5.1 \mathrm{wt} \%$, this amount is acceptable for biological tests. Moreover, it can be upgraded if different xerogel system as $\mathrm{SiO}_{2}-2 \mathrm{~B}_{2} \mathrm{O}_{3}$ are prepared [15].

The tests performed on blood cells showed that the functionalization of NPs with folic acid, introduced to increase NP incorporation in the tumor cells, also provided an important additional advantage in terms of haemocompatibility. Indeed, although $\mathrm{SiBNH} 2$ was able to induce platelet aggregation and neutrophil activation, SiBNH2_F resulted essentially ineffective in activating both cell types.

Acknowledgments Funding by Cariplo (project 2009-2440: Development and safety assessment of nanostructured compounds applicable to boron neutron capture therapy) by Regione Lombardia (SAL-45) and by Almamater Foundation (Pavia) is gratefully acknowledged.

We thank dr. Sushilkumar Jadhav for preliminary experiments.

\section{References}

1. Soloway AH, Tjarks W, Barnum BA, Rong FG, Barth RF, Codogni IM, Wilson JG (1998) Chem Rev 98:1515-1562

2. Tiwari SB, Amiji MM (2006) Curr Drug Deliv 3:219-232

3. Goldberg M, Langer R, Jia X (2007) J Biomater Sci Polym 18:241-268

4. Low PS, Kularatne SA (2009) Curr Opin Chem Biol 13:256-262

5. Yang X, Grailer JJ, Pilla S, Steeber DA, Gong S (2010) Bioconjugate Chem 21:496-504

6. Ciofani G, Raffa V, Menciassi A, Cuschieri A (2009) Nanoscale Res Lett 4:113-121

7. Yao A, Wang D, Fu Q, Huang W, Rahaman MN (2007) Chin Sci Bull 52(2):272-276

8. Nogami M, Moriya Y (1982) J Non-Cryst Solids 48:359-366

9. Irwin AD, Holmgreen JS, Zerda TW, Jonas J (1987) J Non-Cryst Solids 89:191-205

10. Irwin AD, Holmgreen JS, Jonas J (1988) J Non-Cryst Solids 101:249-254

11. Li B, Yue Z, Zhou J, Gui Z, Li L (2002) Mater Lett 54:25-29

12. Soraru GD, Dallabona N, Gervais C, Babonneau F (1999) Chem Mater 11:910-919

13. Soraru GD, Babonneau F, Gervais C, Dallabona N (2000) J Sol-Gel Sci Technol 18:11-19

14. Parashar VK, Orhan JB, Sayah A, Cantoni M, Gijs MAM (2008) Nat Nanotechnol 3:589-594

15. Grandi S, Tomasi C, Cassinelli V, Cucca L, Profumo A, Mustarelli P, Balduini $\mathrm{C}$ (2012) $\mathrm{SiO}_{2}-\mathrm{B}_{2} \mathrm{O}_{3}$ xerogels: the problem of boron leaching. J Non Cryst Solids 358(14):1631-1637

16. Nel A, Xia T, Mädler L, Li N (2006) Science 311:622-627

17. Oberdörster G (2010) J Intern Med 267:89-105

18. Bartneck M, Keul HA, Singh S, Czaja K, Bornemann J, Bockstaller M, Moeller M, Zwadlo-Klarwasser G, Groll J (2010) ACS Nano 4:3073-3086

19. Radomski A, Jurasz P, Alonso-Escolano D, Drews M, Morandi M, Malinski T, Radomski MW (2005) Br J Pharmacol 146:882-893 
20. Guidetti GF, Consonni A, Cipolla L, Mustarelli P, Balduini C, Torti M (2012) Nanomedicine. doi:10.1016/j.nano.2012.04.001

21. Melloni E, Pontremoli S, Michetti M, Sacco O, Sparatore B, Salamino F, Horecker BL (1985) Proc Natl Acad Sci USA 82:6435-6439

22. He YY, Wang XC, Jin PK, Zhao B, Fan X (2009) Spectrochimica Acta Part A 72:876-879
23. Yang SJ, Lin FH, Tsai FC, Wei MF, Tsai HM, Wong JM, Shieh MJ (2010) Bioconjugate Chem 21:679-989

24. Vora A, Riga A, Dollimore D, Alexander KS (2002) Thermochimica Acta 392-393:209-220

25. Gawaz M, Langer H, May AE (2005) J Clin Invest 115: 3378-3384

26. Malech HL, Gallin JI (1987) N Engl J Med 317:687-694 